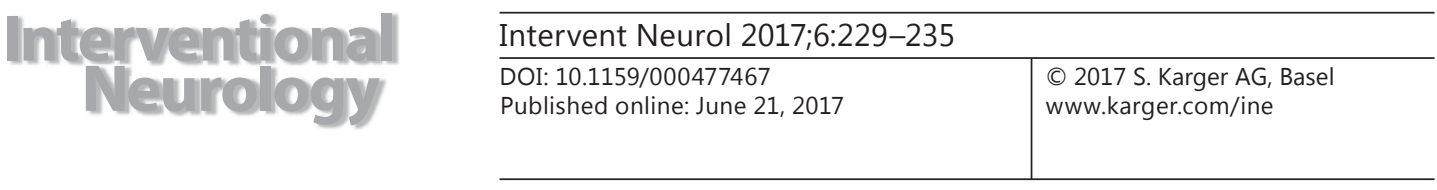

\title{
Septoplasty: Scepter Balloon Angioplasty for Vasospasm after Aneurysmal Subarachnoid Hemorrhage
}

\author{
Bradley A. Gross Daniel A. Tonetti Gregory M. Weiner \\ David M. Panczykowski William J. Ares Cynthia L. Kenmuir \\ Ashutosh P. Jadhav Tudor G. Jovin Brian T. Jankowitz \\ Department of Neurological Surgery, University of Pittsburgh Medical Center, \\ Pittsburgh, PA, USA
}

\section{Keywords}

Vasospasm · Angioplasty · Balloon · Aneurysm · Subarachnoid hemorrhage $\cdot$ Ischemia .

Stroke

\begin{abstract}
Introduction: Balloon angioplasty can be a requisite approach for the treatment of symptomatic and/or severe vasospasm. Dual-lumen microcatheter balloons have multiple potential advantages for this indication including accommodating a 0.014 -inch wire and the potential to deliver superselective vasodilators directly via the microcatheter prior to angioplasty. Methods: The authors reviewed a 3-year institutional experience with the Scepter XC balloon (Microvention, Tustin, CA, USA) in the treatment of postaneurysmal subarachnoid hemorrhage vasospasm, focusing on treatment methods, angiographic, and clinical results. Results: Sixty-four vessels were treated in 18 patients. Fifteen cases were performed under intravenous (i.v.) conscious sedation (83\%). The mean pretreatment stenosis was $59 \%$ (range $40-80$ ), and the mean post-treatment stenosis was $12 \%$ (range $0-40$ ). Five vessels in 3 patients were subsequently retreated via angioplasty for recurrent vasospasm (8\%). There were no complications related to the passage of the balloon microcatheter or inflation of the balloon such as dissection or vessel rupture. Of 14 patients with delayed cerebral ischemia, 7 had complete symptomatic resolution after treatment, and 3 had significant symptomatic improvement. Four patients did not improve after treatment though 3 already had confirmed infarcts on imaging prior to angiography. Conclusion: The Scepter XC is a safe and effective balloon microcatheter for angioplasty of cerebral vasospasm after subarachnoid hemorrhage, allowing for superselective delivery of a vasodilator. Its ease of deliverability and visibility often allows for the performance of the procedure under i.v. conscious sedation.

(c) 2017 S. Karger AG, Basel
\end{abstract}

Bradley A. Gross, MD

Department of Neurological Surgery, University of Pittsburgh, Suite B-400

UPMC Presbyterian, 200 Lothrop Street

Pittsburgh, PA 15213 (USA)

E-Mail Grossb2@ @upmc.edu 


\section{Introduction}

Delayed cerebral ischemia from cerebral vasospasm is a leading cause of delayed neurological morbidity after subarachnoid hemorrhage [1-3]. Medical management via induced hypertension and the maintenance of euvolemia [4] along with intra-arterial infusion of vasodilators [5, 6] are the most common treatment approaches for vasospasm [7]. Balloon angioplasty is a more aggressive approach that can lead to an immediate and often appeasing angiographic result $[8,9]$; however it is associated with a potential added risk of thromboembolic complications and even vessel rupture [10].

The Scepter balloon (Microvention, Tustin, CA, USA) is a versatile, compliant balloon designed for intracranial intervention. Its utility as a balloon adjunct for aneurysm coiling [11], arteriovenous malformation embolization [12-14], and tumor embolization [15, 16] has been described. Its dual coaxial lumen design accommodates a 0.014-inch microwire, allowing for more facile microcatheter delivery, enhanced stability/reduced "watermelon seeding," and the ability to infuse a vasodilator superselectively prior to angioplasty. Two prior small case series have demonstrated the feasibility of this balloon for intracranial angioplasty [17, 18]. In this report, we provide a more detailed analysis of its use with angiographic and clinical results, highlighting our technique of superselective vasodilator infusion and demonstrating the feasibility of the procedure under conscious sedation as well.

\section{Methods}

The authors reviewed a prospectively maintained endovascular database from January 2014 to December 2016 for patients treated with intracranial angioplasty specifically with the Scepter XC $4 \times 11 \mathrm{~mm}$ balloon (Microvention). This search afforded 23 patients; 5 were excluded as they were treated for intracranial stenosis unrelated to postaneurysmal subarachnoid hemorrhage vasospasm. Of note, however, a post hoc review of their treatment results demonstrated no complications after the patients' respective angioplasties. For the remaining 18 patients, the following information was extracted from the database and medical record: patient age, sex, presenting Hunt-Hess grade, Fisher grade, aneurysm location, aneurysm treatment approach, and timing of angioplasty. Patient symptoms prior to treatment and after treatment were noted. Angiographic records were reviewed for treated vessel, baseline vessel diameter (from the original angiogram on presentation), pretreatment vessel diameter, post-treatment vessel diameter, and procedural complications.

All patients in this cohort were maintained in an intensive care unit after aneurysm rupture with close neurological checks and close blood pressure monitoring via an arterial line. They all underwent cerebral angiography on initial presentation to evaluate the entirety of the pial cerebral vasculature. This allowed for baseline calculations of vessel diameter in all patients for this study. Patients are placed on nimodipine on admission, and, once the aneurysm is secured, are allowed to undergo permissive hypertension with careful maintenance of euvolemia through their hospital stay. All patients undergo follow-up digital subtraction angiography on the sixth or seventh day after hemorrhage; neurological deterioration prior to this prompts emergent, earlier angiography for evaluation of vasospasm.

Seven patients were treated awake under intravenous (i.v.) conscious sedation (39\%). Eight patients were already intubated and were maintained under i.v. sedation during the procedure (47\%). Three patients were placed under general endotracheal anesthesia for the procedure (17\%); 2 were treated early in our experience and 1 had significant neurological deterioration and respiratory compromise. Depending on known proximal vessel tortuosity derived from the patient's initial angiogram on presentation, either a 6 French short sheath ( $n=10$ patients, $56 \%$ ) or 6 French shuttle or Neuron MAX catheter ( $n=8$ patients, $44 \%)$ was utilized, the latter in cases of anticipation of triaxial systems for added support. Via the short sheath, either an Envoy catheter $(n=8)$ or Benchmark catheter $(n=2)$ was utilized as a guide for the balloon. Via the Shuttle or Neuron MAX, either a 0.058 -inch Navien $(n=5)$, a 0.044 -inch DAC $(n=2)$, or a CAT $5(n=1)$ was utilized as an intermediate catheter. Via the guide or intermediate catheter, in all cases, the Scepter XC $4 \times 11$ $\mathrm{mm}$ balloon (Microvention) was advanced over a Synchro 0.014-inch microwire into the desired vessel. In most cases $(16 / 18,89 \%), 5 \mathrm{mg}$ of verapamil was superselectively infused via the balloon microcatheter into 


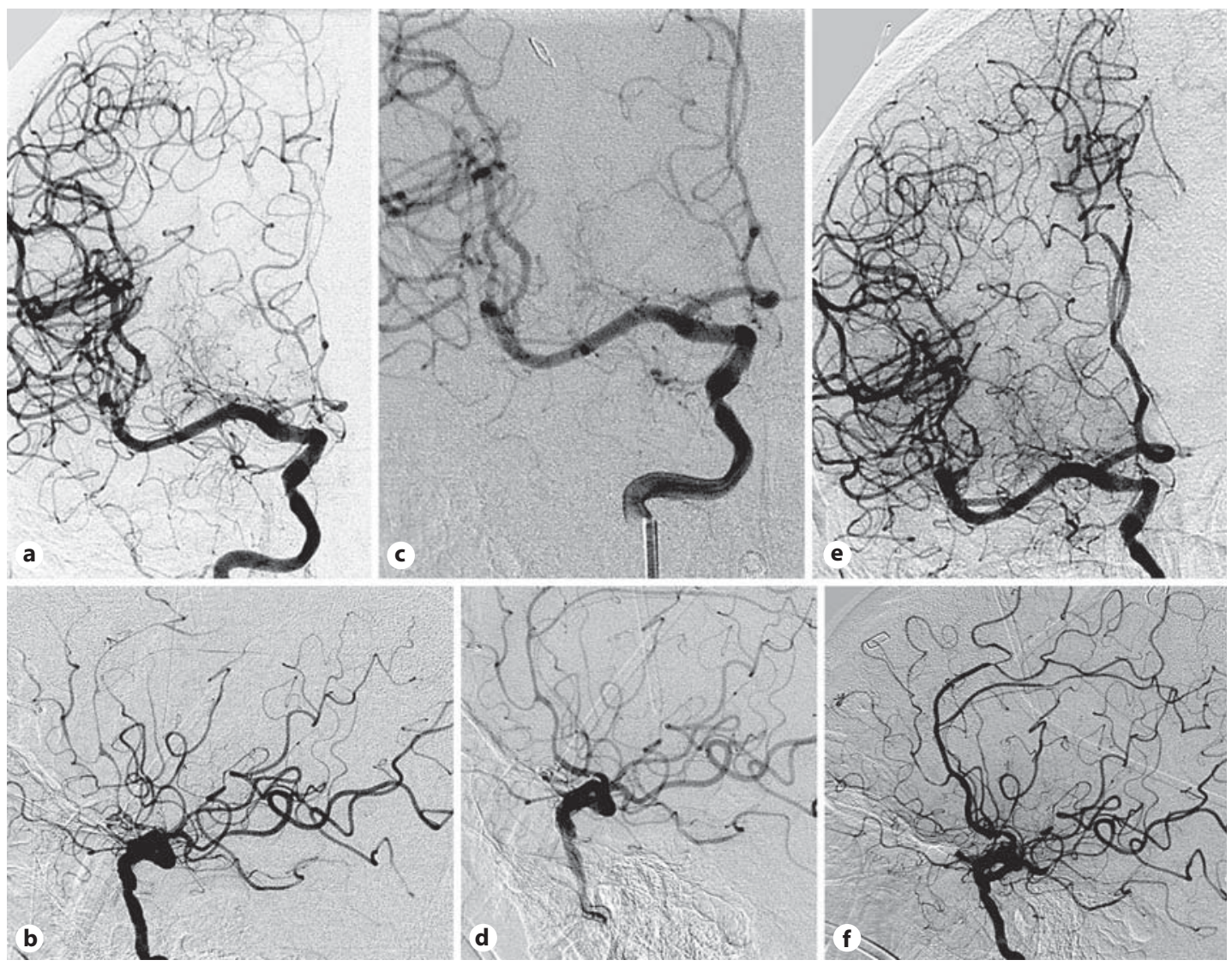

Fig. 1. This patient presented as a Hunt-Hess grade 2 subarachnoid hemorrhage from a ruptured left posterior communicating artery aneurysm treated via clipping. On the fifth day after hemorrhage, he no longer followed commands and developed lower-extremity paraplegia. Anteroposterior (a) and lateral (b) angiography confirmed severe spasm of the right anterior cerebral artery. Via a 6 French Envoy guide catheter in the cervical internal carotid artery, the Scepter XC $4 \times 11 \mathrm{~mm}$ balloon was advanced over a Synchro microwire into the right A2. The microwire was removed, $5 \mathrm{mg}$ of verapamil was slowly infused into the right $\mathrm{A} 2$, and the right A2 followed by the right A1 was treated via balloon angioplasty. Post-treatment anteroposterior (c) and lateral (d) angiography confirm resolution of the right A1 and A2 vasospasm with noteworthy improvement in the caliber of the right A3 and A4. This process was repeated for severe vasospasm in the left anterior cerebral artery territory. Five days later, the patient had recurrent paraparesis; anteroposterior (e) and lateral (f) angiography via the right internal carotid artery confirmed a durable angiographic result in the right A1 and A2 with recurrence of distal anterior cerebral artery vasospasm treated via intra-arterial infusion of verapamil.

the distal target vessel prior to angioplasty. The vessel was then treated via balloon angioplasty from its distal to proximal target (Fig. 1, illustrative case). Of note, in 2 cases early in our experience, initial attempts were made with single-lumen, compliant, dedicated intracranial balloons; however, the balloon and/or microwire would not appropriately track into the target vessel, and thus the Scepter balloon was subsequently utilized.

\section{Results}

Sixty-four vessels were treated via balloon angioplasty with the Scepter XC $4 \times 11 \mathrm{~mm}$ balloon (Microvention) in 18 patients. The mean patient age was 52 years (SD 16), and 78\% of the patients were female. Four patients presented as Hunt-Hess 2 (22\%), 10 patients were Hunt-Hess 3 (56\%), 2 patients were Hunt-Hess 4 (11\%), and 2 patients were Hunt-Hess 5 on 
Table 1. Comparison of pretreatment, post-treatment, and change in the degree of stenosis as well as angiographic recurrence between treated vessels

\begin{tabular}{lrllll}
\hline Vessel & $n$ & $\begin{array}{l}\text { Mean pre-Tx } \% \\
\text { stenosis (range) }\end{array}$ & $\begin{array}{l}\text { Mean post-Tx \% } \\
\text { stenosis (range) }\end{array}$ & $\begin{array}{l}\text { Mean change } \\
\text { (range) }\end{array}$ & $\begin{array}{l}\text { Angiographic recurrence } \\
\text { retreated with } \\
\text { angioplasty, } n(\%)\end{array}$ \\
\hline ICA & 11 & $58(40-80)$ & $8(5-30)$ & $50(40-75)$ & $0 / 11(0)$ \\
M1 & 17 & $63(50-80)$ & $14(0-40)$ & $49(15-75)$ & $1 / 17(6)$ \\
M2 & 4 & $56(45-60)$ & $11(0-25)$ & $45(30-60)$ & $1 / 4(25)$ \\
A1 & 18 & $58(40-80)$ & $14(0-40)$ & $45(20-70)$ & $2 / 18(11)$ \\
A2 & 10 & $54(40-70)$ & $11(0-30)$ & $43(30-60)$ & $1 / 10(10)$ \\
V4/basilar & 4 & $65(55-70)$ & $10(0-20)$ & $56(46-65)$ & $0 / 4(0)$ \\
Total & 64 & $59(40-80)$ & $12(0-40)$ & $47(15-75)$ & $5 / 64(8)$ \\
\hline
\end{tabular}

Pre-Tx, pretreatment; post-Tx, post-treatment; ICA, intradural internal carotid artery; M1, middle cerebral artery first segment; M2, middle cerebral artery second segment; A1, anterior cerebral artery first segment; A2, anterior cerebral artery second segment; V4, vertebral artery fourth segment.

presentation (11\%). One patient had a Fisher 2 bleed pattern; the remaining patients had Fisher 3 subarachnoid hemorrhage patterns with 11 having additional intraparenchymal or intraventricular hemorrhage (Fisher 4). Ruptured aneurysm location was the anterior communicating artery in 6 patients (33\%), the posterior communicating artery in 5 patients $(28 \%)$, and the middle cerebral artery bifurcation in 3 patients (17\%). A ruptured basilar artery, superior cerebellar artery, posterior inferior cerebellar artery, pericallosal, and superior hypophyseal artery aneurysm was identified in 1 patient each. Ten patients were treated via endovascular coiling (56\%), and 8 were treated via microsurgical clip ligation (44\%).

Patients underwent initial angioplasty for cerebral vasospasm at a mean of 7 days after aneurysm rupture (range: 4-11 days). Angiographic results are summarized in Table 1 . The most commonly treated vessels were the A1 (18/64, 28\%) and M1 (17/64, 27\%). In 11 cases, the intradural internal carotid artery was treated (17\%), and in 10 cases, the A2 was treated (16\%). In 4 cases, the M2 was treated (6\%), and in 2 cases each, the V4 and basilar artery were angioplastied (3\% each). Overall mean pre-treatment stenosis was $59 \%$ as compared to the baseline angiogram (range 40-80\%), and the mean post-treatment stenosis was 12\% (range $0-40$ ). This corresponded to a mean change of $47 \%$ (range 15-75). Five vessels were subsequently retreated via angioplasty for recurrent vasospasm (8\%) in 3 patients. One patient had an atypical vasculopathy that required repeat angioplasty of A1 and A2 segments; another patient also required repeat angioplasty of $\mathrm{A} 1$ and $\mathrm{A} 2$ segments. One patient underwent repeat angioplasty for recurrent symptomatic M1 and M2 segment vasospasm. There was no significant difference in the mean pretreatment and post-treatment stenosis between specific treated vessels (Table 1). There was no obvious difference in recurrence rates as the rate for M2 recurrence precludes meaningful comparison in light of the small number of treated M2 vessels.

Fourteen treated patients had neurological deterioration (delayed cerebral ischemia, 83\%), while 4 were obtunded with a poor baseline neurological examination and were being evaluated for angiographic vasospasm empirically. There was 1 procedural complication unrelated to the balloon: an iatrogenic carotid-cavernous fistula secondary to a microwire perforation of the cavernous internal carotid artery. There were no complications directly related to the passage of the balloon microcatheter or inflation of the balloon. Specifically, there were no incidences of dissection or vessel rupture.

Of the 14 patients with delayed cerebral ischemia, 7 had complete symptomatic resolution after treatment, and 3 had significant symptomatic improvement. Four patients did not 
improve after treatment though 3 already had confirmed infarcts on imaging prior to angiography. Three patients had symptomatic recurrence: in 2 , the initially treated segment was retreated with angioplasty, and in 1, the recurrence was secondary to distal vasospasm (Fig. 1). All 3 patients had resolution of their recurrent symptoms after retreatment.

\section{Discussion}

As the primary cause of delayed neurological morbidity after subarachnoid hemorrhage $[2,3]$, it is important to identify risk factors and optimal treatment approaches for cerebral vasospasm. Younger age, worse presenting grade, and diffuse subarachnoid clot are accepted risk factors for vasospasm $[19,20]$. This is well demonstrated in our study cohort of patients with significant vasospasm: half of our treated patients were younger than 50 with a mean age of 52 years; most of them presented as at least grade 3 subarachnoid hemorrhage, and nearly all had diffuse subarachnoid blood. A potential modifiable factor, microsurgical clipping, as compared to endovascular coiling of ruptured aneurysms, has also been identified as a risk factor for vasospasm $[21,22]$. Although beyond the scope of this study, a relatively high proportion of patients in this cohort were treated via microsurgical clip ligation (44\%) as compared to the overall proportion of ruptured aneurysms treated via clipping in the postInternational Subarachnoid Hemorrhage Trial era [23, 24].

In patients with symptomatic and/or severe vasospasm, balloon angioplasty is often a requisite treatment approach in those refractory to medical management. The effect of intraarterial vasodilator therapy is often transient and at times insufficient in this patient population. Innumerable publications have chronicled the evolution of balloon angioplasty in the treatment of postsubarachnoid hemorrhage vasospasm [7-9, 17, 18, 25, 26]. The earliest reports using noncompliant balloons continue to have relevance as multiple interventionalists employ noncompliant balloons today $[8,9,26]$. Putative advantages of noncompliant balloons include greater radial force and a greater selection of balloons in small sizes, allowing for a greater match of balloon-to-vessel size and absolute control of the maximal balloon diameter. The latter may mitigate the most feared risk of vessel rupture.

Dedicated intracranial, compliant balloons generally require less proximal catheter support and allow for easier deliverability as a function of decreased balloon microcatheter stiffness as well as the ability to deliver the balloon without microcatheter exchange. One study that compared the usage of compliant and noncompliant balloons for intracranial vasospasm angioplasty demonstrated no significant difference in the rate of retreatment, new cerebral infarction, and long-term morbidity and mortality between the 2 groups. Despite their presumed lesser radial force, compliant balloons were more likely to achieve a normal or supranormal diameter after treatment [25]. In this series, desired angiographic results were achieved after initial angioplasty in all cases; supplementation with another balloon was not required.

Both single- and dual-lumen-compliant balloon microcatheters are available. Dual-lumen microcatheters such as the Scepter XC (Microvention) allow for the microwire to be removed without the risk of back bleeding into the microcatheter. We use this to our advantage for the treatment of distal cerebral vasospasm as we will typically superselectively infuse a vasodilator prior to angioplasty (Fig. 1). The ability of the microcatheter to accommodate a 0.014 inch microwire is also advantageous as this allows for easier microcatheterization of potentially challenging, spastic vessels. We also agree with other authors that the larger microwire and distal "nose" provide additional subjective stability during balloon inflation $[11,17]$. We typically utilize $100 \%$ contrast and have not had issues with prolonged inflation or deflation times. Furthermore, we were able to use a single balloon for multiple segments with repeated 
inflation/deflation without the need to replace the balloon or use steam to "seal the hole" of the balloon.

The easy deliverability and excellent visibility of the balloon facilitated our ability to perform angioplasty under i.v. conscious sedation in most patients. General endotracheal anesthesia was induced in 3 patients in this series; 2 were treated early in our experience. The ability to treat vasospasm under i.v. conscious sedation has multiple important advantages including the ability to perform the procedure more swiftly in the setting of cerebral ischemia as well as avoiding the risk of hypotension/poor blood pressure control during the induction of anesthesia.

Two initial reports of Scepter (Microvention) usage for cerebral vasospasm nicely demonstrate its feasibility. In 1 series of 7 patients across 2 institutions, there was no reported complication or large vessel recurrence requiring repeat therapy using the Scepter C [18]. Another series of 5 patients also reported no complications using the Scepter XC [17]. Combining results from our experience with these 2 initial series, there were no incidences of vessel dissection, rupture, or direct complications from Scepter usage in 109 treated vessels.

Our usage of the more compliant XC Scepter balloon (Microvention) reflects institutional preference and extrapolative comfort with our usage of this balloon in a variety of other indications such as balloon-assisted coiling and balloon test occlusion. Vessel rupture using the less compliant, Scepter C has been described several times in the embolization literature [12, $14]$, while the usage of the $\mathrm{XC}$ balloon for angioplasty does not seem to compromise angiographic results, as illustrated in this series: mean post-treatment stenosis was $12 \%$ with a range of $0-40$. We thus prefer this more compliant balloon given the excellent angiographic results despite greater compliance of the balloon.

\section{Conclusion}

The Scepter XC is a versatile, easy-to-deliver balloon microcatheter for angioplasty of postsubarachnoid hemorrhage vasospasm. This allowed for the performance of angioplasty under i.v. conscious sedation in many circumstances. The ability to superselectively deliver a vasodilator prior to angioplasty and the low rate of balloon-associated complications are demonstrated in this study.

\section{Disclosure Statement}

No authors have any financial or consulting interests concerning Microvention.

\section{Author Contribution}

B.A.G. drafted the article; all authors participated in the acquisition of data/data analysis, revised the article prior to submission, and had a role in the study supervision.

\section{References}

1 Connolly ES, Rabinstein AA, Carhuapoma JR, Derdeyn CP, Dion J, Higashida RT, Hoh BL, Kirkness CJ, Naidech AM, Ogilvy CS, Patel AB, Thompson BG, Vespa P: Guidelines for the management of aneurysmal subarachnoid hemorrhage: a guideline for healthcare professionals from the American Heart Association/American Stroke Association. Stroke 2012;43:1711-1737.

2 Kassell NF, Sasaki T, Colohan AR, Nazar G: Cerebral vasospasm following aneurysmal subarachnoid hemorrhage. Stroke $1985 ; 16: 562-572$. 
3 Kassell NF, Torner JC, Haley EC Jr, Jane JA, Adams HP, Kongable GL: The international cooperative study on the timing of aneurysm surgery: Part 1 - Overall management results. J Neurosurg 1990;73:18-36.

4 Kassell NF, Peerless SJ, Durward QJ, Beck DW, Drake CG, Adams HP: Treatment of ischemic deficits from vasospasm with intravascular volume expansion and induced arterial hypertension. Neurosurgery 1982;11:337343.

5 Badjatia N, Topcuoglu MA, Pryor JC, Rabinov JD, Ogilvy CS, Carter BS, Rordorf GA: Preliminary experience with intra-arterial nicardipine as a treatment for cerebral vasospasm. AJNR Am J Neuroradiol 2004;25:819-826.

6 Feng L, Fitzsimmons BF, Young WL, Berman MF, Lin E, Aagaard BD, Duong H, Pile-Spellman J: Intraarterially administered verapamil as adjunct therapy for cerebral vasospasm: safety and 2-year experience. AJNR Am J Neuroradiol 2002;23:1284-1290.

7 Rosenwasser RH, Armonda RA, Thomas JE, Benitez RP, Gannon PM, Harrop J: Therapeutic modalities for the management of cerebral vasospasm: timing of endovascular options. Neurosurgery 1999;44:975-979.

8 Eskridge JM, McAuliffe W, Song JK, Deliganis AV, Newell DW, Lewis DH, Mayberg MR, Winn HR: Balloon angioplasty for the treatment of vasospasm: results of first 50 cases. Neurosurgery 1998;42:510-516.

9 Higashida RT, Halbach VV, Dowd CF, Dormandy B, Bell J, Hieshima GB: Intravascular balloon dilatation therapy for intracranial arterial vasospasm: patient selection, technique and clinical results. Neurosurg Rev 1992;15: 89-95.

10 Linskey ME, Horton JA, Rao GR, Yonas H: Fatal rupture of the intracranial carotid artery during transluminal angioplasty for vasospasm induced by subarachnoid hemorrhage. J Neurosurg 1991;74:985-990.

11 Spiotta AM, Miranpuri A, Hawk H, Chaudry MI, Turk AS, Turner RD: Balloon remodeling for aneurysm coil embolization with the coaxial lumen Scepter C balloon catheter: initial experience at a high volume center. J Neurointervent Surg 2013;5:582-585.

12 Jagadeesan BD, Grigoryan M, Hassan AE, Grande AW, Tummala RP: Endovascular balloon-assisted embolization of intracranial and cervical arteriovenous malformations using dual lumen co-axial balloon microcatheters and Onyx: initial experience. Neurosurgery 2013;73(suppl 2):ons238-ons243.

13 Paramasivam S, Niimi Y, Fifi J, Berenstein A: Onyx embolization using dual-lumen balloon catheter: initial experience and technical note. J Neuroradiol 2013;40:294-302.

14 Spiotta AM, James RF, Lowe SR, Vargas J, Turk AS, Chaudry MI, Bhalla T, Janjua RM, Delaney JJ, Quintero-Wolfe $\mathrm{S}$, Turner RD: Balloon-augmented Onyx embolization of cerebral arteriovenous malformations using a duallumen balloon: a multicenter experience. J Neurointervent Surg 2015;7:721-727.

15 Ladner TR, He L, Davis BJ, Yang GL, Wanna GB, Mocco J: Initial experience with dual-lumen balloon catheter injection for preoperative embolization of skull base paragangliomas. J Neurosurg 2016;124:1813-1819.

16 Ladner TR, He L, Lakomkin N, Davis BJ, Cheng JS, Devin CJ, Mocco J: Minimizing bleeding complications in spinal tumor surgery with preoperative Onyx embolization via dual-lumen balloon catheter. J Neurointervent Surg 2016;8:210-215.

17 Heit JJ, Choudhri O, Marks MP, Dodd RL, Do HM: Cerebral angioplasty using the Scepter XC dual lumen balloon for the treatment of vasospasm following intracranial aneurysm rupture. J Neurointervent Surg 2015;7:56-61.

18 Seby J, Spiotta AM, Turner RM, Chaudry MI, Turk AS, Hui F: Initial experience with the coaxial dual-lumen Scepter C balloon catheter for endovascular management of cerebral vasospasm from subarachnoid hemorrhage. J Neurointervent Surg 2014;6:125-128.

19 Charpentier C, Audibert G, Guillemin F, Civit T, Ducrocq X, Bracard S, Hepner H, Picard L, Laxenaire MC: Multivariate analysis of predictors of cerebral vasospasm occurrence after aneurysmal subarachnoid hemorrhage. Stroke 1999;30:1402-1408.

20 Gruber A, Ungersböck K, Reinprecht A, Czech T, Gross C, Bednar M, Richling B: Evaluation of cerebral vasospasm after early surgical and endovascular treatment of ruptured intracranial aneurysms. Neurosurgery 1998;42:258-267.

21 Dumont AS, Crowley RW, Monteith SJ, Ilodigwe D, Kassell NF, Mayer S, Ruefenacht D, Weidauer S, Pasqualin A, Macdonald RL: Endovascular treatment or neurosurgical clipping of ruptured intracranial aneurysms: effect on angiographic vasospasm, delayed ischemic neurological deficit, cerebral infarction and clinical outcome. Stroke 2010;41:2159-2524.

22 Gross BA, Lai PMR, Frerichs KU, Du R: Treatment modality and vasospasm after aneurysmal subarachnoid hemorrhage. World Neurosurg 2014;82:e725-e730.

23 Gnanalingham KK, Apostolopoulos V, Barazi S, O’Neill K: The impact of the international subarachnoid aneurysm trial (ISAT) on the management of aneurysmal subarachnoid haemorrhage in a neurosurgical unit in the UK. Clin Neurol Neurosurg 2006;108:117-123.

24 Molyneux A, Kerr R, Stratton I, Sandercock P, Clarke M, Shrimpton J, Holman R: International Subarachnoid Aneurysm Trial (ISAT) of neurosurgical clipping versus endovascular coiling in 2143 patients with ruptured intracranial aneurysms: a randomised trial. Lancet 2002;360:1267-1274.

25 Miley JT, Tariq N, Souslian F, Qureshi N, Suri MF, Tummala RP, Vazquez G, Qureshi AI: Comparison between angioplasty using compliant and noncompliant balloons for treatment of cerebral vasospasm associated with subarachnoid hemorrhage. Neurosurgery 2011;69(suppl 2):ons161-ons168.

26 Patel A, Griessenauer CJ, Gupta R, Adeeb N, Foreman PM, Shallwani H, Moore JM, Harrigan MR, Siddiqui AH, Ogilvy CS, Thomas AJ: Safety and efficacy of noncompliant balloon angioplasty for the treatment of subarachnoid hemorrhage-induced vasospasm: a multicenter study. World Neurosurg 2017;98:189-197. 